UDC 316.33

LBC 60.27 .9

\title{
ONTOLOGY OF SOLIDARITY AND SOCIAL WORLD
}

\author{
Aleksandr P. Pavlov \\ Siberian Federal University, Krasnoyarsk, Russian Federation
}

\begin{abstract}
This article is devoted to the study of phenomenon of solidarity in terms of social ontology. Attention is paid to the fact that in modern social science, especially in sociology, pragmatic approach dominates in studies of social solidarity according to which solidarity is interpreted as a form and method of social integration of people providing mutual survival, acquisition of vital resources.

However, such approach seems to be insufficient and one-sided since it does not consider for existential ontological constituent of solidarity relations manifested in practices of actors' participation in constituting of social world.

Necessity to consider solidarity as a method of participation of individuals in constitution of social world is substantiated. Social world is interpreted as immediate region of existential co-presence, the region where people feel like co-authors of mutual existence.

The conclusion is made that conventional solidarity is provided by so-called absolute event: sacral event presetting spatial and time boundaries of mutual existence. It is an initial construct of transcendental senses keeping solidarity bonds of people for long time. This article analyzes eidetic, political, and modern types of solidarity, historical interrelation between them is discovered.

Peculiar attention is paid to the fact that in the late $20^{\text {th }}$ - early $21^{\text {st }}$ century large stationary solidarities (for instance, of classes) are already not urgent either as form of social integration or as condition of reproduction of social orders. Instead, principally new type of solidarity appears mainly related with networking methods of production, life's activity, social orders.

This article considers peculiar features of this type of solidarity: mobility, spontaneity, absence of moral obligations of its participants, and so on.

Key words: social order, social existence, social world, event, constituent event, solidarity, political solidarity.
\end{abstract}

УДК 316.33

ББК 60.27 .9

\section{ОНТОЛОГИЯ СОЛИДАРНОСТИ И СОЦИАЛЬНЫЙ МИР}

\author{
Александр Павлович Павлов \\ Сибирский федеральный университет, г. Красноярск, Российская Федерация
}

\begin{abstract}
Аннотация. Данная статья посвящена исследованию феномена солидарности с позиций социальной онтологии. В современном обществознании, особенно в социологии, в исследовании социальной солидарности доминирует прагматический подход, согласно которому солидарность осмысливается как форма и способ социальной интеграции людей, обеспечивающие совместное выживание, обретение необходимых жизненных ресурсов. Однако такой подход представляется недостаточным и односторонним, поскольку не учитывает экзистенциально-онтологической составляющей солидарных отношений, которая проявляется в न практиках участия акторов в конституировании социального мира, мироустроения.

त Автор обосновывает необходимость рассматривать солидарность как способ участия индивидов в процессе конституирования социального мира, мироустроения. Социальный мир осмысливается как непосредственная область экзистенциального соприсутствия, область, в которой люди ощущают себя соавторами совместного с другими бытия.

Автор приходит к выводу о том, что традиционная солидарность обеспечивается так называемым «абсолютным событием» - сакральным событием, задающим пространственно-временные границы со-
\end{abstract}


вместного бытия. Оно является исходным конструктом трансцендентальных смыслов, удерживающих солидарные связи людей на протяжении длительного времени.

В статье рассматриваются эйдетический, политический и современный типы солидарности, раскрывается историческая связь между ними. Во второй половине двадцатого - начале двадцать первого столетия «большие стационарные солидарности» (например, классовые) уже не столь актуальны ни как формы социальной интеграции, ни как условие воспроизводства социальных порядков. Вместо них появляется принципиально новый тип солидарности, прежде всего, связанный с «сетевыми» способами производства, жизнедеятельности, социальными порядками. В статье выделены характерные особенности нового типа солидарности: мобильность, спонтанность, отсутствие моральных обязательств ее участников и т. д.

Ключевые слова: социальный порядок, социальное бытие, социальный мир, событие, учредительное событие, солидарность, политическая солидарность.

Анализ экзистенциально-онтологических оснований солидарности следует начать с изучения близких понятий, с которыми корреспондирует данное. Прежде всего, это понятие «социальный мир». Следует отметить, что социальный мир не является синонимом общества (если понимать под «обществом» некую объективную сущность, надындивидуальную реальность) и не является его частью.

Социальный мир (в дальнейшем для удобства мы будет использовать сокращенное «мир») - это непосредственная область человеческого присутствия, область в которой люди ощущают себя соавторами совместного с другими бытия. Именно в мире преодолеваются экзистенциальные страхи, обретаются онтологическая защищенность и смыслы бытия.

Солидарность не сводится к социальной интеграции. При ближайшем рассмотрении солидарность есть нечто связывающее людей, то, что побуждает их действовать определенным образом в интересах тех групп, с которыми они себя идентифицируют. Интеграция - лишь аспект солидарности. Солидарность есть экзистенциальное соприсутствие акторов в мире, который они считают «своим», собственным. Что значит «собственный мир»? Собственный социальный мир - это всегда мир «изнутри». Аутентичность мира в позиции внутри-находимости. Быть «изнутри» вовсе не означает самоизоляцию мира. Это означает то, что мир существует как целое, и любое сингулярное событие может быть конструктом бытия, только занимая «свое» место внутри мирового хронотопа. То есть можно сказать, что мир изнутри - это мир, непрерывно маркирующий собственные границы.
С позиций социологизма солидарность рассматривается как определенная организация человеческого общежития, позволяющая эффективно использовать ресурсы данного социума для достижения общих коллективных и индивидуальных целей, проявляющаяся во взаимопомощи, взаимозависимости, социальной защищенности и т. д. Т. Парсонс связывает солидарность с ценностным консенсусом как условием системного (социетального) равновесия, в котором заинтересованы все члены общества [8].

Русские религиозные мыслители А.С. Хомяков [15], Н.О. Лосский [7], С.Л. Франк [11] указывают на соборную сущность солидарности, на единение людей в общем духовном организме православной церкви.

Марксистский подход к солидарности основывается на ее социально-классовой природе.

Мы полагаем, что солидарность представляет собой особый механизм связи между сотрудничеством и интеграцией, структурой и действием, структурной детерминированностью и человеческой субъективностью (волей, настроением, ответственностью, доверием и т. д.).

Целый ряд социальных мыслителей, продолжая традицию Э. Дюркгейма, обращает внимание на ритуальный аспект солидарности. В частности, можно назвать исследования И. Гоффмана [21], Р. Коллинза [20].

Английский ученый Р. Коллинз полагает, что в основе солидарности - преддоговорные нерациональные отношения, которые имеют моральную природу. Именно моральные чувства объединяют людей в солидарные сообщества. «Процессы, которые продуцируют эти моральные чувства, - это социальные ритуалы» [6, с. 430]. 
На моральный аспект солидарности указывает также создатель оригинального учения культурсоциологии Д. Александер [18].

Солидарность, безусловно, есть определенная форма общественных отношений. Но при этом важно отметить, что людей объединяет не только потребность совместного выживания, но также потребность «просто быть» (в экзистенциальном смысле). Солидарность - непрерывный процесс коммуникации между людьми, идентифицирующими себя с данной солидарной общностью.

Солидарность самодостаточна. Она не есть механизм совместного бытия. Она и есть совместное бытие, конституирующее себя как собственный мир. В этом качестве солидарность выступает как архитектоника участия, вовлеченности индивидов в процесс миростроительства, мироустроения. «Высший архитектонический принцип действительного мира поступка есть конкретное, архитектоническизначимое противопоставление я и другого. Два принципиально различных, но соотнесенных между собой ценностных центра знает жизнь: себя и другого, и вокруг этих центров распределяются и размещаются все конкретные моменты бытия» [2, с. 66]. Здесь важно отметить характерную для экзистенциально-онтологической солидарности персональную (личностную) идентичность, которую очень тонко «схватил» И. Гоффман. Американский ученый обращает внимание на сочетание двух фундаментальных форм идентификации: категориальной формы (идентификация другого как представителя определенного социальный кластера, категории) и индивидуальной формы, «посредством которой наблюдаемый субъект идентифицируется как уникальная, отличающаяся от всех других личность» [22, p. 3-4].

Солидарность есть такая «захваченность» индивидов общим делом мироустройства, которая превращает их в личности, делает акторами.

Мир, по М. Бахтину, есть такое устроение, в котором каждая его точка захвачена личностью. Личностное тождественно мировому. Все исходит из личностного центра. Человек всегда находится внутри мира как единственного места, в котором он есть то, что он есть: «единственная единственность». Собирание и достраивание мира есть одно- временно собирание и достраивание социальным актором самого себя [2; 3]. В мире каждый причастен к общему делу. Как тонко и образно замечает В. Бибихин, «только в мире человек находит себя - видит в мире себя так, что узнает себя в согласии мира, видит себя в нем, узнавая раньше всякого знания, что только мир ему место и только мир равен ему» [4, с. 59].

Таким образом, можно говорить о единстве двух типов солидарности: прагматического (обусловленного потребностью совместного выживания и обретения необходимых жизненных ресурсов) и экзистенциально-онтологического (солидарная совместность как соприсутствие акторов в собственном мире).

Собственный мир - предмет общей заботы, «домен» бытия, смысловой центр, близость и сопричастность которому делает индивидов акторами собственного бытия. Это то прочное и надежное место, «дом», в который мы всегда возвращаемся (хотя бы в мечтах). «Мы будем понимать под домом нулевую точку системы координат, которую мы приписываем миру, чтобы найти свое место в нем... особый способ жизни, составленный из маленьких и привычных элементов, дорогих нам» [16, с. 550]. «Возвращение»-метафора рекурсивности онтологического ядра, его идентификация и тематизация в процессе воспроизводства мира.

Еще одно условие социальной солидарности - анонимное доверие. Анонимное доверие означает, что социальные отношения вырываются из контекста непосредственной структурной зависимости и связанной с ней системой социального контроля. Но при этом актуализируется другой контекст зависимости: собственно солидарный. Анонимное доверие как проявление солидарности обеспечивается путем передачи части своего онтологического ресурса другим. Солидарность выступает как «онтологическое» равенство: равенство в доступности к совместному бытию, в совместных заботах о мире. В основе анонимного доверия - «верность событию».

Событие поглощает, деперсонализирует человека как трансцендентального субъекта. В этом смысле событие можно уподобить свече, к которой устремляются мотыльки. Событие рождает восторг растворения в транс- 
цендентальном Едином. Не случайно в таких эпохальных политических событиях, как революции, тема смерти, жертвенности особенно актуальна. Но при этом у индивида открывается новая перспектива: получить собственное имя, а вместе с ним и голос в констелляции голосов коллективного Мы. Этот голос дает возможность индивиду в качестве социального актора участвовать в коллективных дискурсах, в режимах вовлеченности, при этом сохраняя и оберегая собственную зону интимности.

Солидарность как онтологическое равенство обеспечивается так называемым абсолютным событием. А.Ф. Филиппов определяет его следующим образом: «Существуют события, которые, так сказать, не "окружены" иными событиями и соотнесены с прочими событиями как индуцирующие, но не индуцируемые. В горизонте событий они носят, как правило, характер предельный. Таковы, прежде всего, события начала и прекращения существования, среди которых для нас важнее всего рождение и смерть. Сюда относятся учредительные события, как подлинные, так и мифические, с которых начинается отсчет хронологии исторических событий. Наконец, сюда относятся события сакральные, то есть обладающие статусом явления трансцендентного в посюстороннем. Все эти события мы относим к разряду абсолютных» $[10$, с. 82$]$.

Учредительные события - это искусственные события, которые необходимы для того, чтобы трансформировать беспокойное, спонтанное, предельно открытое текущее время в упорядоченную темпоральную последовательность. Учредительное событие - это «событие события». С его помощью утверждаются новые дискурсы власти и порядка, устанавливаются правила, «истории», календари, картины бытия и т. д. - все то, что способствует рождению нового мира, новой социальной реальности.

Мы полагаем, что солидарность есть форма коллективного удержания учредительного события. Важнейшая миссия солидарности - ответственность всех и каждого за «дление» события как легитимной законодательной основы социальных миров, которые она порождает и делает «собственными» мирами, мирами «изнутри». Эти миры «захваты- вают» людей в тотальной солидарной интенции: быть с новым миром. Ален Бадью отмечает: «Я должен предельно стойко нести ответственность за последствия - последствия события, его именования, принятых мной обязательств» [1, с. 64].

В XIX в. складываются «большие» солидарности, в которых преобладают формальные обезличенные связи. Речь идет о «переходе от общества личных контактов (или по крайней мере от общества малых групп, где все могли опознать друг друга) к открытому абстрактному обществу, скрепленному не общими целями, а подчинением общим для всех абстрактным правилам» [14, с. 485]. Эпоха гегемонии «больших» анонимных солидарностей (например, классовых) сопровождается появлением новых возможностей для активации субъективных сил индивидов. «Европа, каким ее застал XVI в., была сложным и фрагментарным обществом, целостность которого обеспечивалась сугубо персональными связями. Человек был одновременно включен в различные холистические общности, которые на деле находились между собой в чрезвычайно запутанных отношениях соподчинения, соперничества, конкуренции, противоречия и пр.». «Главным фактором поддержания равновесия внутри этих солидарностей, а равно и между ними, была метафора единого мистического тела» [9, с. 205].

Под метафорой единого мистического тела следует, очевидно, понимать эйдетическую «картину» социальной реальности. «Составить себе картину чего-то значит: поставить перед собой само сущее так, как с ним обстоит дело, и постоянно иметь его так поставленным перед собой» [13, с. 49].

Солидарность в эйдетическом мире, таким образом, - это способ участия людей в охранении трансцендентальных смыслов, заключенных в кодах священного хронотопа: священной истории, инкорпорированной в символически маркированное социальное пространство («социальное тело»). И не имеет значение сословный статус «участника»: рыцарь, крестьянин, священник, богач или нищий - все они акторы общего мирового замысла.

Солидарные связи приобретают форму специфических этосов: ритуальных поведенческих комплексов, реализующихся в призва- 
нии, служении (королю, царю, отечеству, «обществу» и т. д.). Соблюдение ритуальных правил - важнейшее условие воплощения виртуальной (символической) солидарности в солидарность действительную.

На трансцендентальную природу бытия мира обратил внимание немецкий философ К. Ясперс [17]. Как пишет П. Гайденко, «мир, по Ясперсу, не может быть основан на самом себе, он постоянно указывает на свои пределы - на трансценденцию» [5, с. 28].

Подчеркнем, речь идет о возможности экзистенциального со-понимания, экзистенциальной сообщаемости (коммуникации) людей в мире через способы трансцендирования. Обыденная коммуникация сохраняется и «действует» и тогда, когда мир разрушен, когда его уже нет (в экзистенциально-онтологическом смысле). Разве прекращается коммуникация между людьми во времена глобальных перемен и потрясений социального мира, например, в эпоху сокрушения Российской империи в 1917 году?

Мир исчезает тогда, когда его трансцендентальная архитектоника уже не может переводить эйдетические картины мира в план экзистенциального бытия.

Под трансцендентальной архитектоникой понимается пространственно-временная организация мира и ее элементов в виде «шифров» (К. Ясперс), «социокодов» (М.К. Петров), габитусов (П. Бурдье), организующих практик (Э. Гидденс, О. Хархордин), дискурсов (М. Фуко). Она призвана обеспечить не только коммуникацию людей с миром, но и признание индивидами транслируемых миром эйдетических смыслов в качестве их собственного смыслового ядра, цементирующего, собирающего экзистенцию каждого в личностный, персональный план.

Мир всегда разрушается изнутри: изнутри человека, чье личностное ядро уже не может удерживать собственную экзистенцию, которая покидает собственные бытийные пределы, растворяется в бесконечной неопределенности.

Политическая солидарность - это исторический тип солидарности, рождающийся как «противовес» эйдетической солидарности, но в какой-то мере по «лекалу» последней. В конце XVI - начале XVII в. «метафора единого мистического тела рассыпалась. Удержать старые общины-корпорации и тем более массу изолированных индивидов в едином целом призвано было еще одно “открытие”. В этот удивительный период начинается эпоха “грант-нарративов”, эпоха доктрин и идеологий» $[9$, с. 210].

Вместо мистического «социального тела» и священной истории рождается политическое социальное пространство и политическая история, вместо сакральных смыслов, культов - политическая идеология, вместо независимых социальных акторов - политические солидарные группы (классы, партии).

Политическая солидарность рождается из онтологической Пустоты, из невозможности существовать «так, как прежде». И дело тут не просто в нежелании, субъективном неприятии прежнего мира. «Низы» не просто не хотят, они не могут жить по-старому. Старый мир - «немой», он уже не может транслировать смыслы, подпитывающие бытие людей. Он делает невозможной экзистенциальную коммуникацию, поскольку утрачивает единственную надежную связь с бытием людей трансценденцию. В. Франкл пишет: «Универсальные ценности приходят в упадок. Поэтому все большее число людей охватывается чувством бесцельности и пустоты, или, как я это называю, экзистенциальным вакуумом» $[12$, c. 295$]$.

Политическая солидарность одновременно обращена и в прошлое, и в будущее. Политически людей объединяет стремление обрести утерянный мир, вырвать его из захваченности «экзистенциальным вакуумом», собрать в единое, онтологически целое разбросанную, «бездомную» экзистенцию.

С этой целью «заимствуются» некоторые механизмы трансцендирования, характерные для эйдетического мира: сакрализация и мистификация утраченного священного События - истока, «золотого века», а также грядущего «светлого будущего», «царства абсолютной справедливости» (liberté, égalité, fraternité), в том числе идеи хилиазма. Политическая солидарность обретает онтологическую уверенность и прочность благодаря практикам и техникам артикуляции топики сакральной жертвы и жертвенности, героев и вождей, священных заветов отцов и т. д. 
С другой стороны, политическая солидарность основана на артикуляции своего и чужого, друга и врага, Света и Тьмы, Правды и Лжи. Разумеется, эта артикуляция может быть затушевана, сокрыта, например, в дипломатическом этикете. Но она всегда присутствует в политическом мире, поскольку является фактором солидарного настроения, коллективной идентичности, сплачивающих миллионы незнакомых, по сути безразличных друг к другу людей. Таким образом, политическая солидарность есть анонимная солидарность, солидарность несолидарных людей. Она не затрагивает интимных анклавов человеческого бытия.

Политические события могут очаровывать только тех, кто в них принимает непосредственное участие и, быть может, их детей и внуков. Образы героев и врагов, добра и зла со временем «тускнеют». И никакая идеология и пропаганда не способны их реанимировать. Сотни тысяч пропагандистов, агитаторов, учителей, преподавателей «научного коммунизма», истории КПСС, марксистско-ленинской философии и политологии, вся советская пресса и телевидение работали на Систему. Результат всем известен.

Человеческая история свидетельствует об огромных жертвах (в том числе людских) ради торжества Больших нарративов, экзистенциальных прорывов в «светлое будущее», будь то доктринальный коммунизм или националсоциализм. Но человечество устало от войн, революций даже во имя «светлого будущего».

Во второй половине XX - начале XXI столетия появляются принципиально новые типы солидарностей, прежде всего связанные с «сетевыми» способами производства, жизнедеятельности, социальными порядками.

Датский ученый Сёрен Юл (Университет Роскильде, Дания) выделяет три типа солидарности: аффективный, основанный на моральных чувствах, близости, характерных для родственных, семейных связей; конвенциональный, объединяющих людей общими интересами, целями, закрепленными и поддерживаемыми традициями, общими ценностями, а также сознанием взаимной ответственности акторов перед лицом чужаков, «других», представляющих реальную или символическую угрозу солидарному сообществу.
Рефлексивный тип солидарности, характерный для позднего модерна, означает единение людей в современном глобальном мире. «Скрепами» выступают не моральная близость и даже не внешние угрозы со стороны чужаков, а практическая целесообразность взаимодействовать в условиях современных глобальных коммуникаций [23, p. 253-269].

Прежние «большие» стационарные солидарности (например, классовые) уже не столь актуальны ни как формы социальной интеграции, ни как условие воспроизводства социальных порядков. В этих условиях на первый план «выходят» солидарные общности, члены которых не связаны между собой прочными моральными узами. М. Маффесоли называет такие общества новыми племенами: «Племенами следует считать малые группы, генезис и распространение которых парадоксально сопровождает процесс массовизации общества» $[24$, p. 6]. Эти «племена», спонтанно возникающие и спонтанно распадающиеся, лишены выраженных идеологических скрепов.

Новый тип солидарности прагматичен. Его этосы не «заточены» на сохранение единого коллективного пространства («социального тела»). Его просто нет. Современные пространства представляют собой систему разметок, «дресс-кодов», конвенциональных границ, «градов» [19].

При этом можно наблюдать трансформацию абстрактных воображаемых политических пространств в партикулярные пространства, которые конституируются компактными локальными солидарностями, часто маргинальными и далеко не всегда лояльными по отношению к господствующим властным структурам (движения социальных меньшинств, секты, субкультуры и т. д.).

Новый тип солидарности, связанный с «сетевыми» способами производства и жизнедеятельности, обладает специфическими чертами: мобильностью, спонтанностью, отсутствием моральных обязательств его участников и т. д. - и нуждается в дальнейшем исследовании.

\section{СПИСОК ЛИТЕРАТУРЫ}

1. Бадью, А. Философия и событие / А. Бадью. - М. : ИОИ, 2013. - 190 с. 
2. Бахтин, М. М. К философии поступка. Работы 20-х годов / М. М. Бахтин. - Киев : Next, 1994. $383 \mathrm{c}$.

3. Бахтин, М. М. Проблемы поэтики Достоевского / М. М. Бахтин. - М. : Советская Россия, 1979. $320 \mathrm{c}$.

4. Бибихин, В. В. Мир / В. В. Бибихин. - Томск : Водолей, 1995. - 144 с.

5. Гайденко, П. П. Прорыв к трансцендентному: Новая онтология XX века / П. П. Гайденко. М. : Республика, 1997. -495 с.

6. Коллинз, Р. Социологическая интуиция Введение в неочевидную социологию / Р. Коллинз // Личностно-ориентированная социология / П. Л. Бергер, Б. Бергер, Р. Коллинз. - М. : Академический проект, 2004. - С. 399-603.

7. Лосский, Н. О. Мир как органическое целое / Н. О. Лосский // Избранное. - М. : Правда, 1991.- С. 338-484.

8. Парсонс, Т. Система современных обществ / Т. Парсонс. - М. : Аспект Пресс, 1997. - 270 с.

9. Сагомонов, А. Ю. Открытие социального / А. Ю. Сагомонов, П. Ю. Уваров // Одиссей. Человек в истории. - М. : Наука, 2001. - С. 199-216.

10. Филиппов, А. Ф. Sociologia: наблюдения, опыты, перспективы : в 2 т. / А. Ф. Филиппов. СПб. : Владимир Даль, 2015. - Т. 2. -470 с.

11. Франк, С. Л. Духовные основы общества / С. Л. Франк. - М. : Республика, 1992. - 511 с.

12. Франкл, В. Человек в поисках смысла / В. Франкл. - М. : Прогресс, 1990. - 368 с.

13. Хайдеггер, М. Время картины мира / М. Хайдеггер // Время и бытие: статьи и выступления. - М. : Республика, 1993. - С. 41-63.

14. Хайек, Ф. А. Право, законодательство и свобода: современное понимание либеральных принципов справедливости и политики / Ф. А. Хайек. М. : ИРИСЭН, 2006. - 644 с.

15. Хомяков, А. С. Сочинения : прил. к журн. «Вопросы философии» : в 2 т. / А. С. Хомяков. - М. : Моск. филос. фонд : Медиум, 1994. - Т. 2. - 479 с.

16. Шюц, А. Избранное: возвращающийся домой / А. Шюц // Мир, светящийся светом. - М. : РОССПЭН, 2004. - С. 550-557.

17. Ясперс, К. Философия. Кн. 1. Философское ориентирование в мире / К. Ясперс. - М. : «Канон+» РООИ - «Реабилитация», 2012. - С. 58-76.

18. Alexander, J. Morality as a Cultural System: On Solidarity Civil and Uncivil / J. Alexander // Perspectives: Newsletter of the ASA Theory Section. - 2011. - № 33 (2). - P. 1-11.

19. Boltanski, L. De la justification: les economies de la grandeur / L. Boltanski, L. Thevenot. - Paris : Gallimard, 1991. -483 p.

20. Collins, R. Interaction ritual chains / R. Collins. Princeton : Princeton University Press, 2004. - 78 p.
21. Goffman, E. Interaction Ritual: Essays on Face-to-Face Behavior / E. Goffman. - N. Y. : The Penguin Press, 1967. -270 p.

22. Goffman, E. The Interaction Order: American Sociological Association, 1982 / E. Goffman // Presidential Address. American Sociological Review. - 1983. - Vol. 48, № 1 (Feb.). - P. 1-17.

23. Juul, S. Solidarity and social cohesion in late modernity: a question of recognition, justice and judgement in situation // S. Juul // European Journal of Social Theory. - 2010. - Vol. 13, № 2. - P. 253-269.

24. Maffesoli, M. The Time of the Tribes. The Decline of Individualism in the Mass Society / M. Maffesoli. - L. : SAGE Publications : Thousand Oaks, 1996. - 192 p.

\section{REFERENCES}

1. Badyu A. Filosofiya i sobytie [Philosophy and Event]. Moscow, IOI Publ., 2013. 190 p.

2. Bakhtin M.M. K filosofii postupka. Raboty 20-kh godov [To the Philosophy of the Act. Works of 1920s]. Kiyev, Next Publ., 1994. 383 p.

3. Bakhtin M.M. Problemy poetiki Dostoevskogo [Problems of Dostoevsky's Poetics]. Moscow, Sovetskaya Rossiya Publ., 1979. 320 p.

4. BibikhinV.V. Mir [World]. Tomsk, Vodoley Publ., 1995. 144 p.

5. Gaydenko P.P. Proryv k transtsendentnomu: Novaya ontologiya $X X$ veka [Breakthrough to the Transcendent: the New Ontology of the $20^{\text {th }}$ Century]. Moscow, Respublika Publ., 1997. 495 p.

6. Kollinz R. Sotsiologicheskaya intuitsiya. Vvedenie $v$ neochevidnuyu sotsiologiyu [Sociological Insight. An Introduction to Non-Obvious Sociology]. Berger P.A., Berger B., Kollinz R. Lichnostno-oriyentirovannaya sotsiologiya [Person-Oriented Sociology]. Moscow, Akademicheskiyproekt Publ., 2004, pp. 399-603.

7. Losskiy N.O. Mir kak organicheskoe tseloe [The World as an Organic Whole]. Izbrannoe [Selected Works]. Moscow, Pravda Publ., 1991, pp. 338-484.

8. Parsons T. Sistema sovremennykh obshchestv [The System of Modern Societies]. Moscow, Aspect Press, 1997. 270 p.

9. Sagomonov A.Yu., Uvarov P.Yu. Otkrytie sotsialnogo [Discovery of the Social]. Odissey. Chelovek v istorii [Odysseus. Man in History. 2001g]. Moscow, Nauka Publ., 2001, pp. 199-216.

10. Filippov A.F. Sociologia: nablyudeniya, opyty, perspektivy [Sociologia: Observations, Experiments, Perspectives]. Saint Petersburg, Vladimir Dal Publ., 2015, vol. 2. 470 p.

11. Frank S.L. Dukhovnye osnovy obshchestva [Spiritual Foundations of Society]. Moscow, Respublika Publ., 1992. 511 p. 


\section{ФИЛОСОФИЯ}

12. Frankl V. Chelovek v poiskakh smysla [Man in Search of Meaning]. Moscow, Progress Publ., 1990. $368 \mathrm{p}$.

13. Heidegger M. Vremya kartiny mira [Time of Picture of the world]. Vremya $i$ bytie: statyi $i$ vystupleniya [Time and Being: Papers and Speeches]. Moscow, Respublika Publ., 1993, pp. 41-63.

14. Khayek F.A. Pravo, zakonodatelstvo $i$ svoboda: sovremennoe ponimanie liberalnykh printsipov spravedlivosti i politiki [Law, Legislation and Liberty: Modern Understanding of Liberal Principles of Justice and Policy]. Moscow, IRISEN Publ., 2006. 644 p.

15. Khomyakov A.S. Sochineniya: pril. kzhurn. «Voprosy filosofii»: $v 2 t$. [Writings: Appendix to the Journal "Issues of Phylosophy". In 2 vols.]. Moscow, Mosk. filos. fond Publ.; Medium Publ., 1994, vol. 2. 479 p.

16. Shyuts A. Izbrannoe: vozvrashchayushchiysya domoy [The Selected Works: Returning Home]. Mir, svetyashchiysya svetom [The World Glowing with Light]. Moscow, ROSSPEN Publ., 2004, pp. 550-557.

17. Jaspers K. Filosofiya. Kn. 1. Filosofskoe orientirovanie $v$ mire [Philosophy. Book 1 .
Philosophical Orientation in the World]. Moscow, Kanon+ ROOI - Reabilitatsiya Publ., 2012, pp. 58-76.

18. Alexander J. Morality as a Cultural System: On Solidarity Civil and Uncivil. Perspectives: Newsletter of the ASA Theory Section, 2011, no. 33 (2), pp. 1-11.

19. Boltanski L., Thevenot L. De lajustification: les economies de la grandeur. Paris, Gallimard, 1991.483 p.

20. Collins R. Interaction ritual chains. Princeton, Princeton University Press, 2004. 78 p.

21. Goffman E. Interaction Ritual: Essays on Face-to-Face Behavior. New York, The Penguin Press, 1967.270 p.

22. Goffman E. The Interaction Order: American Sociological Association, 1982. Presidential Address. American Sociological Review, 1983, vol. 48, no. 1, pp. 1-17.

23. Juul S. Solidarity and social cohesion in late modernity: a question of recognition, justice and judgement in situation. European Journal of Social Theory, 2010, vol. 13, no. 2, pp. 253-269.

24. Maffesoli M. The Time of the Tribes. The Decline of Individualism in the Mass Society. London, SAGE Publications, Thousand Oaks, 1996. 192 p.

\section{Information about the Author}

Aleksandr P. Pavlov, Candidate of Philosophical Sciences, Associate Professor, Department of Sociology, Siberian Federal University, Prosp. Svobodnyy, 79, bld. 1, 660041 Krasnoyarsk, Russian Federation, sociol@sfu-kras.ru,pavloff56@list.ru.

\section{Информация об авторе}

Александр Павлович Павлов, кандидат философских наук, доцент кафедры социологии, Сибирский федеральный университет, просп. Свободный, 79, корп. 1, 660041 г. Красноярск, Российская Федерация, sociol@sfu-kras.ru, pavloff56@list.ru. 